\title{
Architecture of the critical zone and geometry of the water pathways in the Strengbach CZO (France)
}

\author{
FRANCOIS CHABAUX ${ }^{1}$, CATHERINE LEROUGE ${ }^{2}$, \\ FREDERICK GAL ${ }^{2}$, DANIEL VIVILLE ${ }^{3}$, CORALIE \\ RANCHOUX $^{4}$, JULIEN ACKERER ${ }^{4}$, JEROME VAN DER \\ WOERD $^{5}$, MC PIERRET ${ }^{6}$, THIERRY REUSCHLÉ ${ }^{4}$, \\ PHILIPPE NEGREL $^{7}$ AND CHRYSTEL DEZAYES $^{2}$
}

${ }^{1}$ ITES CNRS UMR 7063 Université de Strasbourg ENGEES

${ }^{2} \mathrm{BRGM}$

${ }^{3}$ ITES (CNRS/U. Strasbourg)

${ }^{4}$ ITES CNRS Unistra ENGEES UMR 7063

${ }^{5}$ Institut Terre et Environnement de Strasbourg CNRS Unistra UMR 7063

${ }^{6}$ ITES

${ }^{7}$ BRGM, France

Presenting Author: fchabaux@unistra.fr

Integration of geological, petrophysical, geochemical and hydrogeological information from six 50 to $120 \mathrm{~m}$-deep boreholes drilled on the Strengbach CZO (OHGE) and from cores recovered for three of the six deep boreholes, allows (1) for reconstructing the architecture of the first $\approx 100$ meters of the critical zone at the scale of the OHGE site, and (2) for proposing a simple conceptual scheme of water circulation in the watershed. The results evidence two different water circulation systems, with a sub-surface circulation in the mobile saprolite horizon and the saprock one and a deeper one in the fractured bedrock, through the fractures that structure this horizon. The data show that the vertical extension of the saprolite and saprock horizons, and thus of the surface aquifer, differ for the various slopes. It is proposed propose to relate such a difference to a variable erosion regime upstream and downstream of a knickpoint in the river-bed. The data also evidence that the deepwater circulation in the fractured bedrock horizon is controlled by regionally oriented fractures, the opening of which are certainly linked to the Tertiary and Quaternary tectonics of the Vosges massif and the Rhine graben, likely through reactivated Hercynian fracture zones. The results on the Strengbach CZO demonstrate the importance of taking into account the geological inheritage of the rocks to understand but also probably to model correctly the hydrogeochemical functioning of the critical zone at the scale of a watershed. Especially, the long-term geological history of the bedrock emplacement or the more recent history of the erosion and quaternary alteration must be considered in details and incorporated to the global view of the system. 